\title{
Resistance in Indian wheat and triticale against loose smut caused by Ustilago tritici
}

\author{
D.P. SINGH ${ }^{1 *}$, A.K. SHARMA ${ }^{1}$, S.S. KARWASRA², S.K. JAIN ${ }^{3}$, S.K. PANT ${ }^{3}$, INDU SHARMA ${ }^{4}$, RITU BALA ${ }^{4}$, \\ V.L. MAJUMDAR ${ }^{5}$ and R.K. BANSAL ${ }^{4}$ \\ 'ICAR-Indian Institute of Wheat and Barley Research, Karnal 132 001, Haryana, India \\ ${ }^{2}$ Department of Plant Pathology, CCS Haryana Agricultural University, Hisar 125 004, Haryana, India \\ 3ICAR-Vivekanada Parvatiya Krishi Anusandhan Sansthan, Almora 263 601, Uttarakhand, India \\ ${ }^{4}$ Department of Plant Pathology, Punjab Agricultural University, Ludhiana 141 004, Punjab, India \\ ${ }^{5}$ Department of Plant Pathology, ARS, Rajasthan Agricultural Research Institute, Durgapura, Jaipur 302 004, Rajasthan, India
}

Received: 19 January 2017/ Accepted: 14 February 2017/ Published online: 23 March 2017

(C) Indian Phytopathological Society 2017

\begin{abstract}
A total of 988 numbers of wheat and Triticale varieties and genotypes were evaluated against loose smut at hot spot locations, Almora in Northern hills zone, Ludhiana, Hisar and Durgapura in North Western plains zone of India under artificially inoculated conditions using local isolates of loose smut (Ustilago tritici) pathogen from 2007-08 to 2011-12 crop seasons. Ninety four genotypes and varieties of wheat and Triticale were found highly resistant (free from infection) whereas 20 genotypes and varieties were found resistant (0.1-5.0\% infection) over years and locations. The wheat varieties, HS 277, KRL 210, MACS 2846, MACS 2971, VL 829 A-9-30-1, GW 1189, HD 4672, HI 8498, HI 8627, HI 8663, MPO 1215, NIDW 295, PDW 233, PDW 291, WH 896 NP 200 were highly resistant. These may be used for breeding for disease resistant as resistant donor parents and resistant wheat varieties may be deployment in disease endemic areas.
\end{abstract}

Keywords: Loose smut, resistant genotypes, triticale, Ustilago tritici, wheat

Loose smut of wheat ( Triticum aestivum L., T. durum Desf. T. dicoccum (Schrank) Schubl.) and Triticale caused by Ustilago tritici (Pers.) Rostr. can cause considerable yield losses in cool and wet climate (Nielsen and Thomas, 1996). Although loose smut of wheat may be controlled effectively using seed treatment with systemic fungicides like carboxin, carbendazim, tebuconazole and thifluzamide (Goel et al., 2001; Sharma et al., 2001), it is not properly practiced by farmers due to high cost and non-availability of fungicides at sowing time in different regions as well as lack of any visible external visible symptoms on infected seeds. The use of Trichoderma viride as seed treatment before sowing could reduce the seed borne infection only to some extent (Singh et al., 2000). The loose smut infected seed looks similar to healthy seeds and that also adds to non adoption of seed treatment. Therefore, use of loose smut resistant varieties is a better option for containing the disease in farmers' fields and reducing the uses of fungicides. Keeping this in view, the high yielding entries in various yield trials and nurseries of three cultivated wheat species and Triticale were evaluated against loose smut of wheat under artificially inoculated condition. This was a practical approach in view of scanty knowledge of DNA markers linked to loose smut resistance gene(s) that could assist the development of loose smut resistant genotypes.

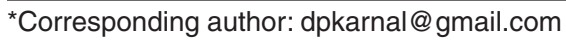

The evaluation of agronomically promising genotypes and released varieties of wheat and Triticale was done at hot spot locations in cooler agro ecological zones (Northern Hills and Northwestern plains zones) of India during 2007-08 to 2011-12 crop seasons. A total of 988 wheat genotypes were tested for loose smut resistance which also included 74 released varieties as well as a highly susceptible variety, Sonalika as check. The total number of genotypes of bread wheat (Triticum aestivum), durum wheat ( $T$. durum), Khapli wheat ( $T$. dicoccum) and Triticale were, 726, 213, 35, and 14, respectively. The hot spot locations were, Almora in Northern hills zone and Ludhiana, Hisar and Durgapura in Northwestern plains zone in India.

Each genotype was sown in a $2 \mathrm{~m}$ long row at 23 cm spacing during mid-November and 5 panicles of each entry were inoculated at pre flowering growth stage ' 59 ' of Zadoks' scale (1974) with freshly collected loose smut teliospores using modified 'Go-go' method (Joshi et al., 1988). The inoculated panicles were covered with butter paper bag. The seeds formed in inoculated panicles were sown for expression of disease in subsequent season. The crop was raised as per recommended agronomic practices and seeds were sown without treatment. The total healthy and loose smutted panicles were counted after its emergence and per cent infected tillers due to loose smut were calculated. The genotypes and varieties free from loose smut infection were categorized as highly 
Table 1. Highly resistant (HR) and resistant (R) of wheat and Triticale genotypes and released varieties to loose smut

\begin{tabular}{|c|c|}
\hline Type of wheat & Genotypes and varieties (c) \\
\hline \multicolumn{2}{|c|}{ Highly resistant (HR or Free from infection) } \\
\hline T. aestivum & $\begin{array}{l}\text { Varieties: HS 277, KRL 210, MACS 2846, MACS 2971, VL } 829 \text { Genotypes: DBW 41, DWR 63, GW 1255, } \\
\text { HD 3016, HD 3065, HPW 348, HW 1095, HW 1096, HW 1097, HW 2308, HW 5304, MACS 2980, MACS } \\
\text { 2981, MACS 2984, MACS 2985, MACS 5004, MACS 5009, MP } 1201 \text { (Q), VL 912, VL 914, VL 924, VL 914, } \\
\text { VL 934, VL 941, WH } 1107\end{array}$ \\
\hline T. durum & $\begin{array}{l}\text { Varieties: A-9-30-1, GW 1189, HD 4672, HI 8498, HI 8627, HI 8663, MPO 1215, NIDW 295, PDW 233, } \\
\text { PDW 291, WH 896 Genotypes: AKDW 3795-3, GW 1236, GW 1244, GW 1245, GW 1250, HD 4719, HI } \\
\text { 8672, HI 8691, HI 8678, HI 8680, HI 8682, HI 8702, HI 8708, HI 8722, MACS 3744, MACS 3660, PDW 308, } \\
\text { PDW 309, PDW 312, PDW 322, UAS 432, WHD } 948\end{array}$ \\
\hline T. dicoccum & $\begin{array}{l}\text { Variety: NP } 200 \text { Genotypes: DDK 1032, DDK 1036, DDK 1037, DDK 1038, DDK 1039, DDK 1040, HW } \\
\text { 1098, MACS 2997, MACS } 5012\end{array}$ \\
\hline Triticale & Triticale genotypes: DT 173, TL 2959, TL 2963, TL 2966, TL 2975 \\
\hline \multicolumn{2}{|c|}{ Resistant (R, having $0.1-5.0 \%$ loose smut infection) } \\
\hline T. aestivum & Variety: PBW 396 Genotypes: HI 8681, HI 8714, HPW 360, HS 541, MACS 3742, UAS 429, WH 1100 \\
\hline T. durum & $\begin{array}{l}\text { Varieties: AKDW 2997-16, HD 4672, PDW } 291 \text { Genotypes: AKDW 4021, MPO 1232, NIDW 505, PDW 313, } \\
\text { PDW } 324\end{array}$ \\
\hline T. dicoccum & Varieties: DDK 1009, DDK 1029 Genotype: DDW 15 \\
\hline Triticale & Genotype: TL 2961 \\
\hline
\end{tabular}

resistant $(\mathrm{HR})$ and those with $0.1-5.0 \%$ average infected tillers were classified as resistant $(\mathrm{R})$.

The loose smut infection in susceptible check Sonalika ranged from $78.8-96.9 \%$ over years and locations indicating successful inoculation. The per cent smut infection in genotypes and varieties tested varied from $0-100 \%$. A total of 94 genotypes and varieties of wheat and Triticale were found highly resistant with zero infection of loose smut whereas 20 genotypes and varieties were found resistant with an average disease ranging from $0.1-5.0 \%$ over years and locations The resistance level to loose smut was highest in case of Triticale $(42.8 \%)$, followed by $T$. dicoccum $(37.1 .3 \%), T$. durum $(23.9 \%)$, and least in T. aestivum $(5.8 \%)$ genotypes and varieties. The bread wheat varieties, HS 277, KRL 210, MACS 2846, MACS 2971, VL 829 durum wheat varieties, A-9-30-1, GW 1189, HD 4672, HI 8498, HI 8627, HI 8663, MPO 1215, NIDW 295, PDW 233, PDW 291, WH 896 and Khapli wheat variety NP 200 were highly resistant to loose smut besides other genotypes. The resistant varieties to loose smut were, PBW 396, AKDW 2997-16, HD 4672, PDW 291 in durum, DDK 1009, and DDK 1029 in Khapli wheat (Table 1). These genotypes may be used as resistant donor parents for breeding for disease resistance in wheat and Triticale, and released varieties for deployment in disease endemic areas toward containing yield losses and reducing use of seed dressing systemic fungicides.

Role of T. durum and Triticale could be important in bringing down the loose smut incidence in wheat in cooler regions of India. The loose smut resistant bread wheat varieties, VL 829, KRL 210 and HS 277 in Northern hills zone and durum wheat varieties PDW 233, PDW 291 and WH 896 in North Western plains zone, can be used to manage the disease effectively. These genotypes of wheat and Triticale are in addition to those reported resistant to loose smut (Singh et al., 2000, 2002).
The varieties highly susceptible ( $>50 \%$ infection) to loose smut were: C 306, DBW 14, DBW 17, DBW 39, DL 788-2, DPW 621-50, GW 322, HD 2733, HD 2888, HD 2864, HD 2932, HD 2967, HD 2985, HD 4672, HI 1500, HI 1563, HS 240, HS 295, HS 507, HPW 251, HW 2044, K 8027, K 0307, HUW 234, KHARCHIA-65, KRL 19, LOK-1, MACS 6222, MACS 2971, MACS 2496, MP 3288, MP 4010, MPO 1215, NI 5439, NIAW 1415, NW 2036, NW 2036, PBW 175, PBW 343, PBW 373, PBW 396, PBW 550, PBW 590, PDW 314, PDW 315, Sonalika, VL 804, VL 892, VL 907, WH 1021, WH 1080 and WHD 943. It is, therefore, recommended to use seed treatment in these varieties with systemic fungicides for management of loose smut in Northern hills and North western and Eastern plains zones of India.

The resistant and susceptible genotypes identified may be used for studies on genetics of loose smut resistance in wheat since the available information in this field is scanty. The genetics of loose smut resistance in an F5 derived recombinant inbred line (RIL) population of 94 lines from the cross of resistant genotype AC Foremost with a susceptible genotype BW278 to $U$. tritici race T10 was studied by earlier worker (Kassa et al., 2012; Knox and Menzies, 2012). A single gene, designated Ut6, segregated for resistance to race T10 in the RIL population. A modified bulked segregant analysis identified a microsatellite marker linked to Ut6. The loose smut resistance gene Ut6 mapped to the long arm of chromosome 5B. Five microsatellite markers mapped within $6.7 \mathrm{cM}$ of Ut6. A diverse set of wheat lines was haplotyped for Ut6 using the linked microsatellite markers gpw5029 and barc232. The microsatellite markers associated with Ut6 will be useful for markerassisted selection of loose smut resistant wheat lines (Kassa et al., 2012). Nielsen and Thomas (1996) concluded on resistant genes to loose smut based o that genes can provide partial or completely resistance and 
can be either dominant or recessive. The resistance stops the growth of the pathogen at one or more sites, e.g. in the ovary, embryo or seedling; although the embryo is genetically susceptible, the penetration of the fungi can sometimes be blocked by resistant maternal tissue of the ovary. Knox et al. (2012) identified four major and one minor QTL after crossing resistant and susceptible parents to loose smut. The wheat varieties may also be bred in future for loose smut resistance in addition to rusts and other foliar diseases for cooler climate of South Asian countries toward reducing use of fungicides and preventing yield losses.

\section{REFERENCES}

Goel LB, Singh DP, Sinha VC, Singh Amerika, Singh KP, Tewari AN, Beniwal MS, Karwasra SS, Aujla SS and Grewal AS (2001). Efficacy of Raxil (tebuconazole) for controlling the loose smut of wheat caused by Ustilago segetum var. tritici. Indian Phytopath. 54: 270-271.

Joshi LM, Singh DV and Srivastava KD (1988). Manual of Wheat Diseases. Malhotra Publishing House, New Delhi. p. 75.

Kassa Mulualem T, Menzies Jim G and McCartney Curt A (2014). Mapping of the loose smut resistance gene Ut6 in wheat (Triticum aestivum L.). Mol. Breed. 33: 569576.
Knox R and Menzies J (2012). Resistance in wheat to loose smut. In: Sharma, I. (Ed.) Disease resistance in wheat. CAB International. pp. 160-189.

Nielsen J and Thomas P (1996). Loose Smut. In: Wilcoxson RD and Saari EE (Eds.) Bunt and Smut Diseases of Wheat: Concepts and Methods of Disease Management. Mexico, D.F.: CIMMYT.

Sharma AK, Singh DP, Kumar J, Singh Amerika, Tewari AN, Singh KP, Karwasra SS and Grewal AS (2001). Efficacy of thifluzamide in the control of loose smut of wheat caused by Ustilago segetum var. tritici. Indian J. agric. Sci. 71:648649.

Singh DP, Sharma AK, Kumar J, Goel LB, Karwasra SS, Beniwal MS and Grewal AS (2002). Resistant lines to loose smut (Ustilago segetum var. triticl) in wheats (Triticum aestivum, T. durum, T. dicoccum) and triticale. Indian J. agric. Sci. 72 : 308-310.

Singh DP, Nagarajan S, Goel LB, Singh D, Kumar J, Singh DV, Singh Amerika, Srivastava KD, Aggarwal Rashmi, Beniwal MS, Tewari AN, Singh KP and Grewal AS (2000). Efficacy of Trichoderma viride in controlling of loose smut of wheat caused by Ustilago segetum var. tritici at multilocation. J. Biol. Cont. 14: 35-38.

Singh DP, Sharma AK, Karwasra SS, Pant SK, Sharma Indu and Majumdar VL (2008). Nature of resistance in wheat and Triticale to loose smut. Indian Phytopath. 61: 528-529.

Zadoks JC, Chang TT and Konzak CF (1974). A decimal code for the growth stages of cereals. Weed Res. 14: 415-421. 